\title{
Microclimas do município de Viçosa do Ceará: Uso da temperatura efetiva na análise do conforto térmico
}

\author{
Microclimates in Viçosa - CE: \\ using the effective temperature in the analysis of thermal comfort. \\ SANTOS JÚNIOR ${ }^{1}$, J. B.; CASTRO ${ }^{2}$, L. M. S. P.; ALVES ${ }^{3}$, E. R.; SALES ${ }^{4}$, M. C. L. \\ jairgeoufc@gmail.com
}

\begin{abstract}
Resumo
A análise foi realizada no município de Viçosa do Ceará, cujos fatores geoambientais permitem um tipo climático de maior umidade e menor temperatura efetiva, de acordo com o constatado nas medições. O principal fator que se pode destacar é a altitude do município, que se diferencia em meio às áreas mais rebaixadas do Estado, que dão forma a depressão sertaneja. O objetivo da pesquisa é evidenciar como o conforto térmico é influenciado pelas diferentes zonas microclimáticas existentes dentro de Viçosa do Ceará. A escolha dos pontos visou averiguar as características naturais que causam diferentes microclimas, observar aspectos do constante crescimento urbano que afeta os climas locais de cada ponto em questão e prover uma comparação com os levantamentos de 2009, no período caracterizado como quente e seco. Estes foram analisados através do levantamento de dados de temperatura do ar, temperatura efetiva, umidade do ar e altitude durante a prática de campo do dia 08 de maio de 2016. Esse momento se constitui dentro do período do outono no hemisfério sul, correspondente aos meses de chuva no nordeste setentrional.
\end{abstract}

Palavras-chave: Conforto térmico. Microclima. Viçosa do Ceará.

\begin{abstract}
The analysis was performed in the county of Viçosa do Ceará, whose the geo-environmental factors allow a climate type of high humidity and effective temperature low, according to the observed in measurements. The main factor that can be highlighted is the altitude of the county, which differs among the most recessed areas of the state forming the backwoods depression. The objective of the research is to evidence the thermal comfort is influenced by the different microclimates within the Viçosa do Ceará. The choice of points intends ascertaining the natural characteristics that cause different microclimates, observe aspects of constant urban growth that affects the local climate of each item concerned and provide a comparison to the 2009 search, the period characterized as hot and dry. These were analyzed by lifting air temperature data, effective temperature data, humidity data and altitude data during the day of field practice May 08, 2016. This time it's in autumn period in the southern hemisphere, corresponding to months rain in the northern northeast.
\end{abstract}

Keywords: Thermal comfort. Microclimate. Viçosa - CE.

\section{INTRODUÇÃO}

O espaço urbano sempre esteve e está em constante modificação. As cidades são os exemplos mais evidentes de transformação do espaço pela sociedade. Dessa forma, o ambiente urbano caracteriza-se por possuir diferentes áreas utilizadas de diversas formas, tais usos definirão esses espaços, como áreas de lazer, centros comerciais, áreas residenciais, áreas industriais, entre outras. Esse espaço urbano fragmentado com diferentes usos além de interferir no social, político e econômico terá como reflexo um microclima.

Segundo Monteiro \& Mendonça (2003), uma das destacadas vertentes de análise dos climas urbanos na atualidade se refere ao campo termo-higrométrico, no qual são desenvolvidos estudos

\footnotetext{
${ }^{1}$ Jair Bezerra dos Santos Júnior, graduando em Geografia e vinculado ao Laboratório de Climatologia Geográfica e Recursos Hídricos (LCGRH/UFC), Universidade Federal do Ceará, Fortaleza - CE, Brasil

${ }^{2} L i g i a$ Maria Silva Pereira Castro, graduanda em Geografia e vinculada ao Laboratório de Climatologia Geográfica e Recursos Hídricos (LCGRH/UFC), Universidade Federal do Ceará, Fortaleza - CE, Brasil

${ }^{3}$ Eduardo Rodrigues Alves, graduando em Geografia e vinculado ao Programa de Educação Tutorial (PET Geografia/UFC), Universidade Federal do Ceará, Fortaleza - CE, Brasil

${ }^{4}$ Marta Celina Linhares Sales, prof ${ }^{a}$ doutora do dept ${ }^{o}$ de Geografia, Coordenadora do Laboratório de Climatologia Geográfica e Recursos Hídricos (LCGRH/UFC), Universidade Federal do Ceará, Fortaleza - CE, Brasil
} 
sobre ilhas de calor e de frescor, de inversões térmicas e de conforto/desconforto térmico. Dessa forma, este trabalho busca realizar uma análise do clima do município de Viçosa do Ceará, dando atenção principalmente às alterações térmicas e higrométricas produzidas no espaço urbano.

Os espaços analisados de acordo com suas utilidades e variações geográficas configuram-se como ilhas de calor ou ilhas de frescor. Os estudos da formação dessas ilhas evidenciam a área de ocupação do solo, que tendem a influir, notoriamente, em como a população se sente dentro desses ambientes, tornando-os capacitados de classificação pelo conforto térmico.

A ilha de calor denuncia as modificações feitas pelo homem da camada basal da atmosfera através das diferenças dos tipos de uso da terra e coberturas entre os espaços urbanos. A ilha de calor se caracteriza pelo aumento da temperatura urbana, enquanto a ilha de frescor demonstra o contrário. São áreas que geralmente possuem uma cobertura vegetal maior, sendo assim, apresentam temperaturas mais amenas. Essa vegetação, de modo geral, influencia na atuação da radiação solar, na medida em que intercepta, absorve, reflete e transmite essa radiação, captando e transpirando água.

De acordo com Andrade (2005) o microclima reflete a influência de elementos urbanos individuais e de seus arranjos mais elementares, como edifícios e as suas partes constituintes, ruas e praças, pequenos jardins, entre outros. Logo, ao caracterizar os elementos de cada espaço tem-se a oportunidade de compreender o microclima deste.

O espaço urbano dissertado neste trabalho é o de Viçosa do Ceará, inserido na unidade geoambiental da Serra da Ibiapaba. A localização do município incorpora condições climáticas com temperatura medianas durante todo o ano e precipitação média de 1.349 mm (CEARÁ, 2015), já que está situada em área de barlavento recebendo ventos úmidos do litoral. Consiste em uma área na qual, através das análises realizadas nos pontos, encontra-se maior umidade e menor temperatura quando comparado com o restante do contexto ambiental do Estado.

Os levantamentos foram realizados durante o mês de Maio de 2016 que está inserido dentro do período chuvoso da cidade (CEARÁ, 2015). O principal sistema meteorológico vigente nessa época do ano no Nordeste brasileiro é a Zona de Convergência Intertropical (MENDONÇA \& DANNI-OLIVERA, 2007). Diferente do levantamento de Peixoto \& Sales (2012) em outubro 2009 - apresentado por eles como período seco -, desta vez os dados teriam a atuação da ZCIT como fator climático.

Definida por Ferreira \& Mello (2005) como uma banda de nuvens que contorna a faixa equatorial do globo terrestre que tem sua formação por meio da confluência dos ventos alísios do hemisfério norte com os ventos alísios do hemisfério sul. De acordo com estes autores, essa zona é o fator mais importante na determinação das chuvas no setor norte do Nordeste do Brasil. A 
nebulosidade densa que foi observada durante as medições elucida esse período e influenciam nas temperaturas ao refletirem os raios solares mantendo a superfície protegida (MENDONÇA \& DANNI-OLIVEIRA, 2007).

\section{METODOLOGIA}

Após trabalhar a estrutura teórica, utilizando de referências literárias de cunho climatológico durante uma preparação para o campo, o objeto de estudo foi estabelecido. O município de Viçosa do Ceará se constitui em uma área de $1.311,59 \mathrm{~km}^{2}$ e está a 685 metros de altitude. Localizada na microrregião da Ibiapaba e na mesorregião noroeste do Ceará. Suas feições de localização são de extrema importância para as características climáticas estarem classificadas como Tropical Quente Semiárido Brando e Tropical Quente Subumido, apresentando temperaturas médias de 22 a $24{ }^{\circ} \mathrm{C}$ (CEARÁ, 2015). A seguir, na figura 01, observa-se a localização do munícipio de Viçosa do Ceará em relação ao Estado do Ceará.

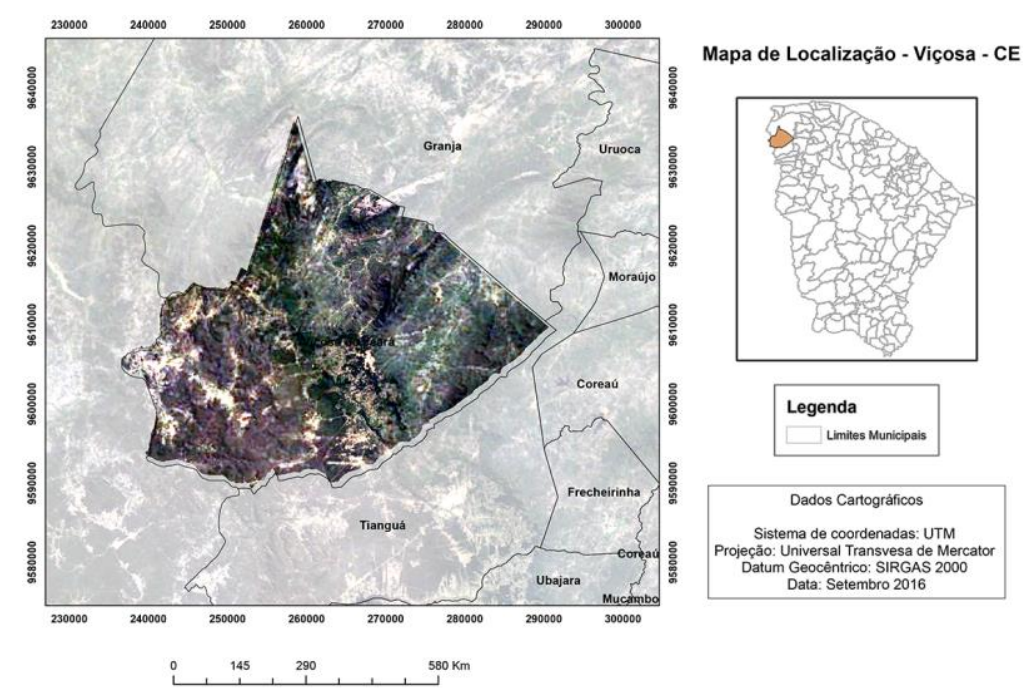

Figura 01. Mapa de Localização - Viçosa do Ceará. Fonte: Castro (2016)

Os pontos dos levantamentos estabelecidos foram os seguintes:

- Ponto 01 - Praça Pedro II: latitude 03 34' 19" S e longitude $41^{\circ} 05^{\prime}$ ' 89” O, com altitude de 670 metros. Principal aspecto é a presença de uma lagoa, com vegetação ornamental em seu entorno e o calçadão coberto por pedra portuguesa de coloração clara (figura 02);

- Ponto 02 - Mercado Central: latitude de $03^{\circ} 34^{\prime} 03^{\prime \prime} \mathrm{S}$ e longitude de $41^{\circ} 05^{\prime} 27^{\prime \prime} \mathrm{O}$, com altitude de 706 metros. Localizado no centro da cidade onde todas as ruas são asfaltadas e possui significante fluxo de pessoas (figura 03); 
- Ponto 03 - Praça do Coreto: latitude de $03^{\circ} 33^{\prime} 35^{\prime}$ ' S e longitude $41^{\circ} 05^{\prime} 28^{\prime \prime} \mathrm{O}$, com altitude de 715 metros. É uma área aberta à circulação de ventos e definido como área verde; o piso da praça é em sua maioria na cor cinza, mas em seu entorno todas as ruas de acesso são asfaltadas (figura 04);

- Ponto 04 - Igrejinha do Céu: latitude $3^{\circ} 33^{\prime} 54^{\prime}$ S e longitude $41^{\circ} 05^{\prime} 41^{\prime} \mathrm{O}$, com altitude de 760 metros. É o ponto mais próximo da vegetação nativa, sendo esta a característica de boa parte do espaço (figura 05).

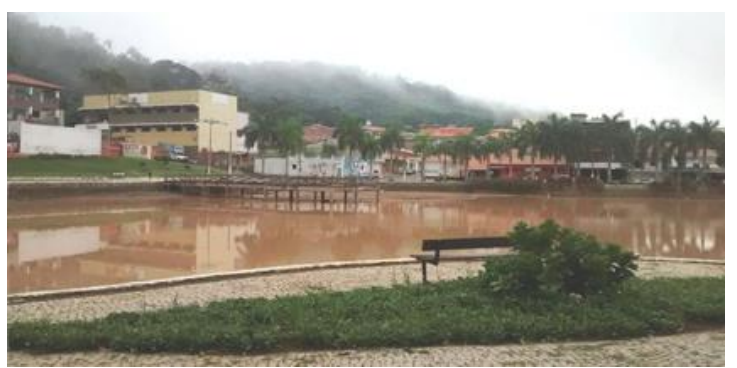

Figura 02. Ponto 01. Fonte: Gomes (2016).

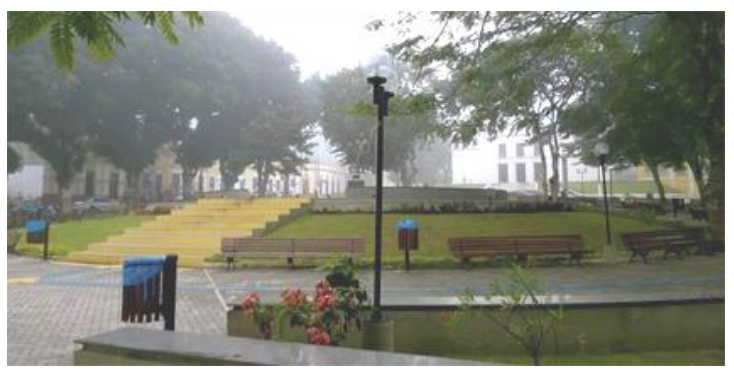

Figura 04. Ponto 03. Fonte: Almeida (2016).

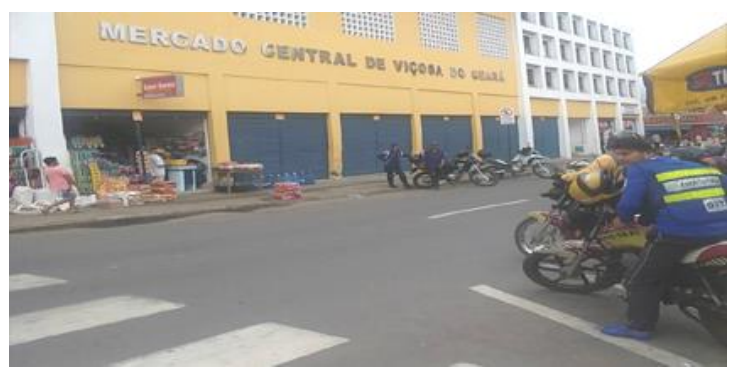

Figura 03. Ponto 02. Fonte: Almeida (2016).

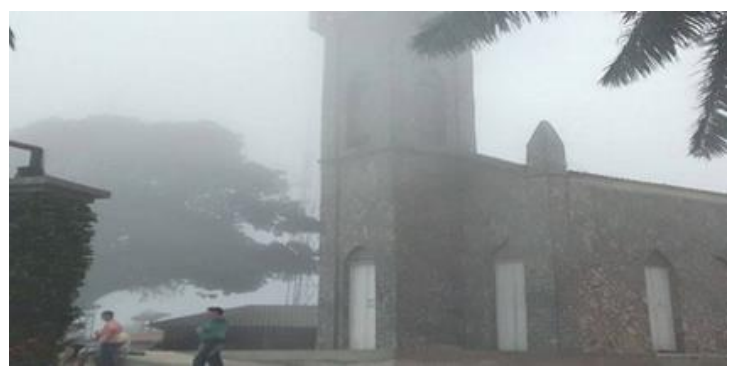

Figura 05. Ponto 04. Fonte: Gomes (2016).

Durante a prática foram utilizados instrumentos que possibilitaram a realização de medições necessárias para a compreensão climatológica de cada ponto. Psicrômetros giratórios e equações proporcionaram a coleta dos dados de temperatura do ar, temperatura do ar saturado, umidade relativa do ar, temperatura efetiva e sensação térmica. As temperaturas efetivas foram resultados da equação T. E. ${ }^{\circ} \mathrm{C}=0,4$ (T. S. + T. U.) $+4,8$, onde T. S. e T. U. são a temperatura do ar e a temperatura do ar saturado, respectivamente. Para o dado da porcentagem da umidade do ar foi utilizada a tabela Psicrométrica. A sensação térmica foi definida através do Diagrama do Conforto Humano retirado do Instituto Nacional de Meteorologia. Foram decididas essas formas de dados, pois o propósito da pesquisa é evidenciar como o conforto térmico é influenciado pelas diferentes zonas microclimáticas existentes dentro do objeto de estudo. 


\section{RESULTADOS E DISCUSSÃO}

\subsection{PONTO O1 - PRAÇA PEDRO II}

Caracterizado pela presença de uma lagoa, é compreendido por um microclima com aspectos semelhantes ao dos outros pontos da cidade, onde pela manhã e ao fim da tarde a umidade do ar no local é elevada e a sensação térmica varia entre "muito úmida" e "confortável" durante todo o dia. A presença da lagoa interfere diretamente no microclima por exercer um papel importante na umidade do ar, pois a variação desta tem implicações profundas por atuar significantemente na dinâmica atmosférica. (VAREJÃO-SILVA, 2006).

No ponto 01 , às 8 horas se encontrou $96 \%$ de umidade relativa, com baixa visibilidade e ocorrência de névoa espessa e temperatura efetiva $\operatorname{com} 22,56^{\circ} \mathrm{C}$ (tabela 01 ). Ao longo do dia pôdese constatar uma baixa variação de temperatura e umidade do ar, com apenas $2,64{ }^{\circ} \mathrm{C}$ de amplitude térmica do total da série e a mínima umidade em $64 \%$ às 15 horas. Os dados dão visibilidade à influência da lagoa na temperatura atmosférica do local, como constante regulador da umidade atmosférica.

Ao utilizar o recorte de Peixoto \& Sales (2012) pode-se encontrar a temperatura efetiva no mesmo ponto com máximas equivalentes, porém em horários diferentes. Em 2016, foi obtida a máxima de $25,56^{\circ} \mathrm{C}$ às 15 horas, já em 2009, a mesma temperatura fora captada às 13 horas (tabela 01). O crescimento urbano da cidade pode ter influenciado esse aumento de temperatura. Características da lagoa foram modificadas com o tempo. Observa-se que as reformas da Igrejinha do Céu, localizada no ponto de maior altitude da cidade, acarretaram o processo de assoreamento da lagoa. E esta se encontra ameaçada, devido o entulho, que prejudica o procedimento de evaporação que influência a dinâmica atmosférica, evidenciada anteriormente.

Tabela 01. Temperatura efetiva do ponto 01 captada nos anos de 2009 por Peixoto \& Sales e em 2016 por Santos Júnior. A temperatura mais baixa obtida está destacada em verde e a mais alta em vermelho. Fonte: Santos Júnior (2016).

\begin{tabular}{|c|c|c|c|c|c|c|c|c|c|c|}
\hline \multicolumn{11}{|c|}{ TEMPERATURA EFETIVA EM ${ }^{\circ} \mathrm{C}$ DO PONTO 01 - PRAÇA PEDRO II } \\
\hline món & $8 \mathrm{~h}$ & $9 \mathrm{~h}$ & $10 \mathrm{~h}$ & $11 \mathrm{~h}$ & $12 \mathrm{~h}$ & $13 \mathrm{~h}$ & $14 \mathrm{~h}$ & $15 \mathrm{~h}$ & $16 \mathrm{~h}$ & $17 \mathrm{~h}$ \\
\hline 2009 & 22,4 & 23,6 & 23,2 & 22,4 & 24,4 & & 24,8 & 24,8 & 23,6 & 23,6 \\
\hline 2016 & 22,56 & 23,16 & 23,6 & 23,84 & 24,4 & 24,5 & 24,24 & 25,2 & 24,36 & 23,56 \\
\hline
\end{tabular}

\subsection{PONTO O2 - MERCADO CENTRAL}

O ponto 02 é caracterizado pelo fluxo comercial. A ocupação do solo, os prédios no espaço, a impermeabilização do solo, a pouca arborização do ponto e a quantidade de calor sensível 
irradiado propiciam temperaturas altas quando comparado com os outros pontos de medição na cidade. Propriedades como estas citadas indicam a formação de ilha de calor. Diferente do ponto 01, onde encontra-se uma ilha reguladora de temperatura, no ponto 02 o fenômeno da ilha de calor pode ser percebido através do desconforto térmico.

Como pode ser analisado na Tabela 02, as temperaturas efetivas se mantiveram em constante aumento até o horário de 13 horas, quando atingiu a máxima temperatura e pela primeira vez no dia apresentou umidade relativa abaixo dos $60 \%$, sendo a mínima umidade de todos os pontos. Essa temperatura perdurou até às 14 horas, sendo padrão dentro da ilha de calor a manutenção das máximas, que conservou o fluxo do calor latente até este horário e voltou a esfriar durante o fim da tarde quando a umidade tornou a aumentar - chegando a $92 \%$-, mantendo-se entre 25 e $23^{\circ} \mathrm{C}$.

Durante as 13 e 14 horas, a sensação térmica se enquadrava na classificação "necessita de vento para conforto". Ao que tudo indica, as ruas onde se constitui o mercado são construções desregulares, estreitas e curtas. Dessa forma, a circulação e a direção dos ventos podem se diferenciar dos outros pontos, sendo boa parte desses ventos bloqueados pelas edificações do entorno, contribuindo para a perda da qualidade do conforto térmico. Exemplos como este evidenciam o mau uso e ocupação do solo local, propiciando a formação do fenômeno da ilha de calor no centro da cidade. Outro fator que pesa sobre a temperatura efetiva do ponto 02 é a altura das construções do entorno e a coloração destas, contendo aspectos de tons mais escuros. Essa coloração escura diminui a porcentagem do albedo do ponto 02 , absorvendo maior energia térmica neste espaço.

Tabela 02. Temperatura efetiva do ponto 02 captada nos anos de 2009 por Peixoto \& Sales e em 2016 por Santos Júnior. A temperatura mais baixa obtida está destacada em verde e a mais alta em vermelho. Fonte: Santos Júnior (2016).

\begin{tabular}{|c|c|c|c|c|c|c|c|c|c|c|}
\hline Horário & $8 \mathrm{~h}$ & $9 \mathrm{~h}$ & $10 \mathrm{~h}$ & $11 \mathrm{~h}$ & $12 \mathrm{~h}$ & $13 \mathrm{~h}$ & $14 \mathrm{~h}$ & $15 \mathrm{~h}$ & $16 \mathrm{~h}$ & $17 \mathrm{~h}$ \\
\hline 2009 & 22,4 & 23,2 & 23,6 & 24 & 25,2 & 25,4 & 25,8 & 26 & 24,8 & 24,8 \\
\hline 2016 & 23 & 24 & 24 & 25 & 25 & 26 & 26 & 25 & 25 & 24 \\
\hline
\end{tabular}

\subsection{PONTO O3 - PRAÇA DO CORETO}

O ponto 03 é um espaço de convivência que se tornou importante para a cidade, pois é nela que se situa a Igreja Matriz de Viçosa do Ceará, além de ser onde pode-se encontrar muitas construções históricas. Essas construções têm como característica as cores claras em suas fachadas, 
o que contribui significantemente para a elevação do albedo e o alívio das temperaturas. Outro destaque é a arborização da área, que tem parte de sua extensão coberta com gramado.

As ruas, por se organizarem em função da praça, tornaram-se corredores que potencializam a circulação dos ventos, influindo na sensação térmica "confortável" até mesmo às 14 horas, quando foi registrada a máxima medição termal efetiva. Durante o período da manhã, das 8 às 10 horas, foi captada sensação térmica "muito úmida" e com o decorrer do aumento da temperatura do ar, ao chegar a tarde, seguiu até às 16 horas na situação “confortável”. É curioso, então, ressaltar o valor da ação de fatores, como a ventilação, onde no mesmo horário, nos pontos dois e três, encontram-se as máximas temperaturas efetivas destes com pouca diferença, mas já no ponto 02 a sensação térmica destacava a necessidade do vento para o melhor conforto (tabela 03).

Tabela 03. Temperatura efetiva do ponto 03 captada nos anos de 2009 por Peixoto \& Sales e em 2016 por Santos Júnior. A temperatura mais baixa obtida está destacada em verde e a mais alta em vermelho. Fonte: Santos Júnior (2016).

\begin{tabular}{|c|c|c|c|c|c|c|c|c|c|c|}
\hline \multicolumn{11}{|c|}{ TEMPERATURA EFETIVA EM ${ }^{\circ} \mathrm{C}$ DO PONTO 03 - PRAÇA DO CORETO } \\
\hline Horário & $8 \mathrm{~h}$ & $9 \mathrm{~h}$ & $10 \mathrm{~h}$ & $11 \mathrm{~h}$ & $12 \mathrm{~h}$ & $13 \mathrm{~h}$ & $14 \mathrm{~h}$ & $15 \mathrm{~h}$ & $16 \mathrm{~h}$ & $17 \mathrm{~h}$ \\
\hline 2 & 2,4 & 3,3 & 21, & 24,8 & 25,2 & 26 & 26 & 26 & 25,6 & 25,6 \\
\hline 2016 & 22,8 & 23,2 & 22,6 & 23,8 & 23,2 & 24,4 & 25,4 & 24,8 & 24 & 23,6 \\
\hline
\end{tabular}

Ao utilizar novamente do recorte de Peixoto \& Sales (2012) nas medições do mesmo ponto, pôde-se observar a disparidade dos dados de temperatura efetiva nos anos (tabela 03). Segundo os autores, existe a ocorrência de uma ilha de calor onde encontram-se temperaturas de 25 até $26{ }^{\circ} \mathrm{C}$ durante todo o período da tarde, e este fenômeno é justificado pelo asfalto nas mediações da Praça do Coreto, o tipo de materiais empregados e a má circulação dos ventos proporcionados pelas construções que a rodeiam. De fato todos esses elementos urbanísticos interferem no conforto térmico do ponto 03 e devem ser ressaltados.

Inicialmente, na Tabela 03, encontram-se os dados foram obtidos no mês de Outubro de 2009, temporada de altas temperaturas e baixos índices de umidade. Em seguida, na mesma tabela, encontram-se dados captados durante o mês de Maio de 2016, que é um período do ano da "quadra chuvosa" no nordeste setentrional. Essa relação de períodos indica quando fenômenos são intensificados dentro do mesmo espaço, como as ilhas de calor, que atingem mais ainda os moradores de Viçosa do Ceará na época mais quente e seca, modificando toda a estrutura temporalclimática da cidade. 


\subsection{PONTO 04 - IGREJINHA DO CÉU}

A Igrejinha do Céu, citada anteriormente por ser o ponto de maior altitude da cidade, apresentou disparidades em suas características durante as novas medições. Em outubro de 2009, de acordo com Peixoto \& Sales (2012), a máxima umidade relativa captada no ponto 04 foi $83 \%$ e a temperatura do ar mínima com $22^{\circ} \mathrm{C}$, às 8 horas; em maio de 2016, obteve-se boa parte das medições acima dos $90 \%$ em umidade relativa e com temperatura efetiva máxima com 23,6 (tabela 04).

Segundo Varejão-Silva (2006), nos Trópicos a altitude constitui um fenômeno enfático na determinação de áreas de maior conforto térmico. Isto justifica a altitude do ponto 04 ser o principal agente gestor dessa situação térmica. Além disso, o ponto em questão tem boa disposição de vento, por sua posição topográfica favorável, definindo boa parte do quadro de sensação térmica na faixa de "muito úmido". Nos horários das 8 às 10 horas e também às 17 horas a umidade do ar esteve saturada, contando com baixa visibilidade e formação de névoa.

Portanto no ponto 04 é identificado como ilha de frescor (PEIXOTO \& SALES, 2012) que, além de uma localização privilegiada, tem uma composição paisagística natural estampada. A vegetação observada é bastante densa e ajuda a regular a temperatura do ambiente, pois essas árvores de médio e alto porte atuam como obstáculo à radiação solar direta, diminuindo a disponibilidade de energia para aquecer o ar (MENDONÇA \& DANNI-OLIVEIRA, 2007).

Tabela 04. Temperatura efetiva do ponto 04 captada nos anos de 2009 por Peixoto \& Sales e em 2016 por Santos Júnior. A temperatura mais baixa obtida está destacada em verde e a mais alta em vermelho. Fonte: Santos Júnior (2016).

\begin{tabular}{|c|c|c|c|c|c|c|c|c|c|c|}
\hline \multicolumn{11}{|c|}{ TEMPERATURA EFETIVA EM ${ }^{\circ} \mathrm{C}$ DO PONTO 04 - IGREJINHA DO CÉU } \\
\hline Horário & $8 \mathrm{~h}$ & $9 \mathrm{~h}$ & $10 \mathrm{~h}$ & $11 \mathrm{~h}$ & $12 \mathrm{~h}$ & $13 \mathrm{~h}$ & $14 \mathrm{~h}$ & $15 \mathrm{~h}$ & $16 \mathrm{~h}$ & $17 \mathrm{~h}$ \\
\hline 2009 & 22,4 & 23,3 & 21,5 & 24,8 & 25,5 & 26 & 26 & $\angle 0$ & 25,6 & 25,6 \\
\hline 2016 & 21,6 & 21,6 & 22,4 & 22,8 & 22,8 & 23,1 & 22 & 23,2 & 23,6 & 21,6 \\
\hline
\end{tabular}

\subsection{ANÁLISE DAS PRODUÇÕES CARTOGRÁFICAS}

As cartas reproduzem a alteração da temperatura efetiva dos quatro pontos de $13 \mathrm{~h}$ e $15 \mathrm{~h}$ da tarde. As ilhas de calor conservaram uma temperatura elevada no período da tarde. O que influenciou na temperatura dos pontos foi a forma como esses espaços são utilizados. Percebe-se que o ponto 04 se manteve com uma temperatura efetiva mais amena, enquanto os outros pontos da cidade apresentaram um aumento (figura 06 e figura 07).

Essa intensificação é explicada, sobretudo pela presença do asfalto e dos tipos de materiais de construção utilizados que aumentam o calor irradiado e consequentemente aumentam a 
temperatura efetiva constantemente e gradualmente nos horários entre $13 \mathrm{~h}$ e $15 \mathrm{~h}$ no ponto 01 , no ponto 02 e no ponto 03 que são locais, que, em relação ao ponto 04, mais den samente urbanizados e menos arborizados evidenciando-se como ilhas de calor urbanas.

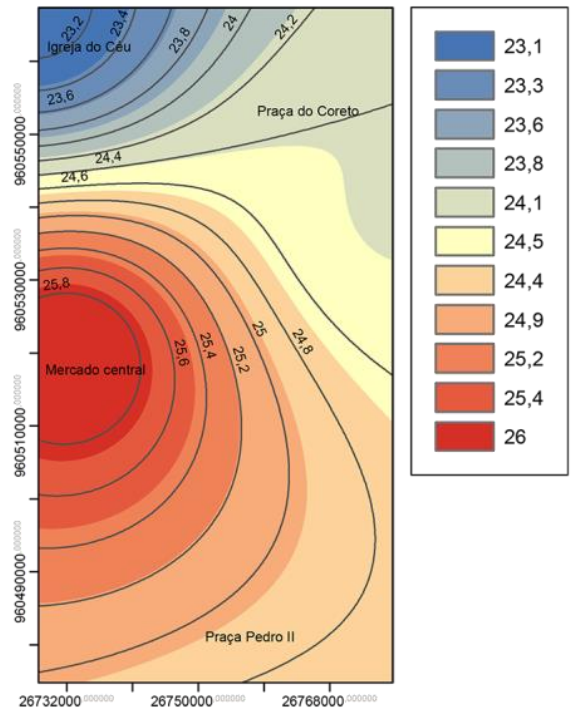

Figura 06. Distribuição espacial da temperatura efetiva às 13 h. Fonte: Castro (2016).

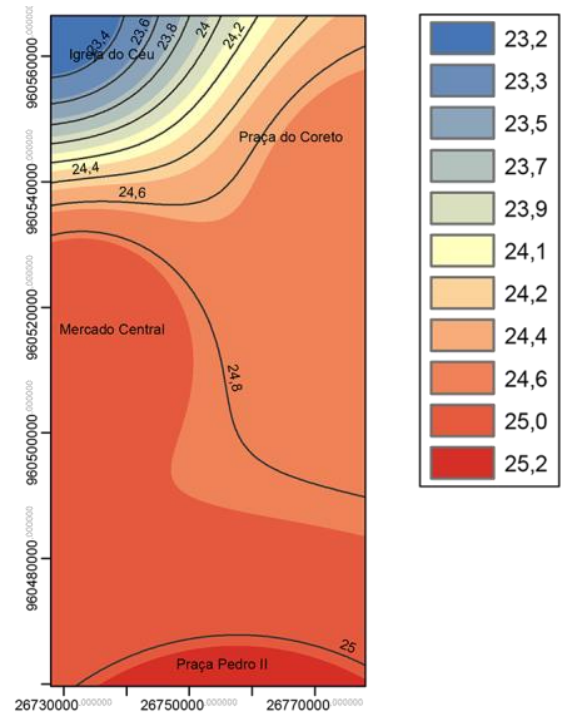

Figura 07. Distribuição espacial da temperatura efetiva às 15 h. Fonte: Castro (2016).

\section{CONSIDERAÇÕES FINAIS}

Em todo o município foi possível evidenciar os elementos que constituem o clima, assim como os fatores que dão qualidade ao mesmo. Ressalta-se também a importante diferenciação das paisagens que vai desde o porte da vegetação encontrada em cada espaço até a altitude dos pontos, notório pela sensibilidade humana. Durante a caracterização pôde-se observar que a população está ciente das mudanças microclimáticas e tem conhecimento sobre o efeito dos elementos nessa modificação, pois tem total percepção sobre como se sente confortável em cada local.

Verifica-se durante o levantamento que o processo urbanístico tornou o ponto 02 uma notória ilha de calor, isto pode ser concluído desde 2009. Este processo atualmente tem tido efeito na alteração do microclima do ponto 01, que no ano de 2009 foi classificado por Peixoto \& Sales (2012) nas medições dele como uma ilha de frescor. Identifica-se o ponto $01 \mathrm{com}$ um elemento que ainda consegue agir como regulador da umidade do ar, porém de forma menos efetiva.

Estudar esse comportamento climático é importante para evidenciar o processo de urbanização desenfreado que cidades interioranas têm passado, como em Viçosa do Ceará. A caracterização aqui fornecida pode contribuir com a gestão territorial inserida no meio urbano, auxiliando com intervenções e reeducando a população, propondo providencias em prol do alívio do desconforto térmico (PEIXOTO \& SALES, 2012). 


\section{REFERÊNCIAS}

ANDRADE, H.; O clima urbano - Natureza, Escalas de análise e aplicabilidade. Finisterra, vol. 40, n. 80. Lisboa: 2005.

CEARÁ. INSTITUTO DE PESQUISA E ESTRATÉGIA ECONÔMICA DO CEARÁ. Caracterização geográfica. In Perfil Básico Municipal 2015 - Viçosa do Ceará. Disponível em: http://www.ipece.ce.gov.br/publicacoes/perfil_basico/pbm-2015/Vicosa_do_Ceara.pdf. Acesso em: 28/04/2016.

FERREIRA, A. G.; MELLO, N. G. S.; Principais sistemas atmosféricos atuantes sobre Nordeste do Brasil e a influência do Oceano Pacífico e Atlântico no clima da região. Revista Brasileira de Climatologia, vol. 1, n. 1. Curitiba: 2005.

INMET - INSTITUTO NACIONAL DE METEOROLOGIA (BRASIL). In Diagrama do Conforto Humano. Disponível em: http://www.inmet.gov.br/html/clima/conforto_term/. Acesso em: 28/04/2016.

MENDONÇA, F.; DANNI-OLIVEIRA, I. M.. Climatologia: noções básicas e climas do Brasil. 1 ed. São Paulo: Oficina de Textos, 2007. 206 p.

MONTEIRO, C. A. F; MENDONÇA, F.. Clima Urbano. 1 ed. São Paulo: Contexto, 2003. 192 p.

PEIXOTO, F. S.; SALES, M. C. L.. Análise de Microclimas na Cidade de Viçosa do Ceará: Abordagem na Perspectiva do Conforto Térmico. Revista Brasileira de Geografia Física, vol. 5, n. 1. Recife: 2012.

VAREJÃO-SILVA, M. A.. Meteorologia e Climatologia. Versão digital 2. Recife, 2006. 345 p.

\section{AGRADECIMENTOS}

Agradecemos inicialmente aos nossos pais pelo apoio durante a realização deste trabalho. Agradecemos a todos os envolvidos no processo de levantamento durante a prática do campo e à professora doutora Marta Celina Linhares Sales, que nos guiou com toda sua sapiência.

Recebido em: 14/08/2016

Aceito para publicação em: 01/10/2016 